\title{
Editorial: A New Year for a Developing Journal
}

\author{
by Sarah A. Curran PhD, BSc(Hons) ${ }^{1}$ 四
}

\author{
The Foot \& Ankle Journal 2 (1): 4
}

Published: January, 2009

This is an Open Access article distributed under the terms of the Creative Commons Attribution License. It permits unrestricted use, distribution, and reproduction in any medium, provided the original work is properly cited. (The Foot \& Ankle Journal (www.faoj.org)

$\mathbf{T}_{\text {he arrival of }} 2009$ is the ideal time to review the achievements of The Foot \& Ankle Journal in 2008 and to look forward to the forthcoming year. The popularity and international status of this journal is evolving with 2008 publications from the US, Germany, China, India, Australia, New Zealand and United Kingdom. It is hoped that the beginning of 2009 and future issues of The Foot \& Ankle Journal will cover a wide variety of topics related to the foot and ankle that are informative and critical in nature. The continued evolvement of The Foot \& Ankle Journal is principally due to the hard work, commitment and vision of Al Kline, DPM - the originator and Technical Editor-in-Chief of the journal. During 2008 , the journal secured ISSN registration and it is hoped that for 2009 it will be listed with various database internet programs through the National Library of Medicine.

$$
\text { “...what turns a looker into a reader"? }
$$

The Foot \& Ankle Journal is the first open-access electronic journal dedicated to publishing articles primarily covering topics dealing with foot and ankle medicine and surgery. It has a number of attractive characteristics. These include publication of a manuscript usually within one month, and no subscription fee.

Address correspondence to: Dr. Sarah A. Curran PhD, BSc(Hons), Chief Editor, The Foot \& Ankle Journal

${ }^{1}$ Lecturer, Wales Centre for Podiatric Studies, University of Wales Institute, Cardiff, Western Avenue, Cardiff, CF5 2YB, United Kingdom

Direct line: +44 (0) 292041 7221. Email: scurran@uwic.ac.uk of particular appeal will be the future development and inclusion of short video clips of This latter feature is appealing certainly within the economic downturn which we are all experiencing at the present time. Perhaps surgical and clinical procedures set within manuscripts. This will enhance the clarity and content of the case reports, and facilitate communication with fellow healthcare professionals. The journal receives submissions from established surgeons and clinicians in the field of foot and ankle medicine. However, an important and clear aim is to encourage submissions from interns and residents as well as professionals from other healthcare disciplines.

The challenges and demands faced by clinicians and surgeons today are to provide up-to-date medical care to their patients by incorporating valid and new information. However, whilst clinical experience can be considered as a justifiable basis of knowledge, it is frequently used to inform scientific enquiry. Although considered low in the hierarchy of evidence (category III) information derived from case reports on many occasions set the scene for higher forms of evidence-based-medicine to be performed (i.e. randomized controlled trials, category I).

The purpose of The Foot \& Ankle Journal is to present a systematic approach to clinical, surgical and technical problems of the foot and ankle encountered in podiatric and orthopedic practice. 
The focus throughout all of the past issues has been based on practical and theoretical issues of patient management presented in the format of case reports. However, in December's 2008 issue 2 manuscripts were published that presented original research ${ }^{2}$ and an evidence-based-medicine review. ${ }^{3}$

It is hoped that by continuing with the publication of case reports and extending submissions to original research and critical reviews will further develop the content, classification and delivery of The Foot \& Ankle Journal. These forms of publications however will also be accompanied by the clinical quiz which is intended to convey the message that learning should be enjoyable! Guidelines for submission of manuscripts are provided below.

\section{Guidelines for submission of manuscripts}

The Foot \& Ankle Journal accept the following type of submissions:

- Case reports

- Critical Appraisal/literature review

- Original research

- Technical and clinical tips

- Letter to the editor

- Clinical/photo quiz

\section{i) Title}

Should represent the content and breadth of the material reported.

\section{ii) Author information}

Name, degree, affiliation and address of all contributing authors should be provided. Email address and telephone number is required for the corresponding author.

\section{iii) Abstract}

This section provides a summary of key information of the manuscript. For case reports, critical appraisal/literature reviews and technical/clinical tips the abstract is unstructured providing 'to the point information' using no more than 150 words. For original research submissions the traditional IMRAD structure is used which provides the following 4 sections: Introduction and aim (why the research was done), Methods (what was done), Results (what was found) and Discussion (the interpretation of the findings - clinical and/or theoretical perspective). No more than 250 words should be used for a structured abstract.

\section{iv) Keywords}

Keywords should be presented below the abstract. Up to 5 single words or short phrases may be included and should cover the main aspect of the manuscript. Authors are encouraged to use the terms listed as Medical Subject Headings (MESH) in Index Medicus (Medline) found at http:www.medline.com

\section{v) Introduction/background/aim}

This section should set the scene by providing pertinent information about the problem being presented and/or studied. Gaps within the existing literature, critical analysis and any conflicting evidence should be highlighted. The aim of the manuscript should be clearly stated. If the submission is based on original research a hypothesis/hypotheses or a research question should be provided.

\section{vi) Method (original research)}

The selection of participants (including how they were recruited) and setting of where the data was obtained should be described clearly. The design of the study should be stated, and the methods, equipment and materials should be provided in enough detail so they can be reproduced in future work. Full details of any randomization process must be provided (i.e. control versus placebo, selection of treatment). 
Information on ethical approval should be included. Details of statistical analysis and statistical analysis software package used (i.e. Statistical Package for the Social Sciences [SPSS] and version) to perform the analysis should be provided.

\section{vii) Results}

Results should be presented in a clear and logical manner. Information from all participants should be included, unless otherwise stated. The main important findings should be highlighted and only present actual data. Summarise findings using tables and charts but avoid repeating this information in the main text.

\section{viii) Discussion and conclusion}

This section should begin with a restatement of the aim of the study. The main discussion should build on and extend beyond the results, and consideration should be given to methodological issues as and where appropriate. Observations from the study should be related to previous studies (i.e. support or conflicting findings). The contributions of the study should be clearly stated and ideas for further research should be highlighted. The implications (clinical and theoretical) and limitations of the findings should also be discussed. The conclusion should correspond with the main findings of the study with a key message.

\section{ix) Figures and tables}

To support the clarity of the main body text, figures such as schematic, photographs, graphs and tables are encouraged. Figures or tables taken from previous published material will require evidence of copyright permission that should accompany the original submission.

\section{x) References}

Please use numerical references (i.e. ${ }^{1-3}$ ) and list in order of appearance. When sending the manuscript, please format the reference numbers as Superscript. For the main text, when an author's surname is used and 3 or more authors are listed for the article 'et al' must be used (i.e. Banks, et al.,) The following are examples for journal, book and internet references:
Examples:

Journal:

Nishi H, Miyamoto S, Minaminura H, Ishikawa T, Katoh Y, Shimizu Y. Pseudoaneurysm of the dorsalis pedis artery causing neurologic deficit. Annals of Vascular Surgery. 18 (4): 487 - 489, 2004.

Book:

Munro BH, Page EB. Statistical Methods for Health Care Research. 2nd ed. J.B. Lippincott Co, Philadelphia, Pennsylvania, 1993.

Internet:

Saglimbeni AJ, Fulmer CJ. Achilles tendon injuries and tendonitis. http://www.emedicine.com/pmr/topic219.htm Accessed date required.

\section{xi) General}

Before using abbreviations they should be presented in full (i.e. Intraclass correlation coefficients [ICC]). Garamond style font should be used throughout. The main text and figure/table legends should be in size 12 font whilst the reference section and table contents should be in size 10 font. All subheadings should be in bold.

\section{xii) Additional guidance for case reports}

Authors are referred to Scott Malay's editorial on the value of an interesting case. The full reference is as follows: Malay SD. The value of an interesting case. Journal of Foot and Ankle Surgery. 46 (4): 211 - 212, 2007.

\section{Method of submission}

All articles submitted to be considered for publication in The Foot \& Ankle Journal should be sent to: picomstaff@hotmail.com or faojeditors@gmail.com as an attachment to an email. Please name your article by presenting the author's first initial and last name (i.e. SCurran). Submissions will be reviewed for their clinical and scientific merit and relevance to the journal. Authors will be informed of the status of their submission via email within a period of approximately 3 weeks. Once accepted articles are uploaded in PDF and HTML format. 


\section{In appreciation:}

On behalf of Al Kline, DPM (Technical Editorin-Chief) and myself we would like to thank all contributing authors, and associate editors for their hard work and dedication. We would also like to express our gratitude to the manuscript reviewers for 2008:

Robert J. Spinner, MD

Dane K. Wukich, MD

Jarrett Cain, DPM, AACFAS

Ron Bilow, MD

Art W. Simonetti, LPN, MBA

\section{References}

1. Howie JW. Writing and speaking in medicine BMJ 3: 1113 - 1125, 1976.

2. Watson CP, Boland RA, Refshauge $\mathrm{KM}^{*}$ Measurement Reliability of swelling in the acute ankle sprain. The Foot \& Ankle Journal 1 (12): 4, 2008.

3. Turlik M. Evidence based medicine review: Comparison of negative pressure wound therapy using vacuum-assisted closure with advanced moist wound therapy in the treatment of diabetic foot ulcers. The Foot \& Ankle Journal 1 (12): 5, 2008. 